\title{
Correction to: Evaluating the impact of the KETS on GHG reduction in the first phase
}

\section{Sung-Hyun Jun ${ }^{1} \cdot$ Jee Young $\mathrm{Kim}^{2} \cdot \mathrm{Hyungna}^{\mathrm{O}} \mathrm{h}^{3}$}

Published online: 15 June 2021

(C) Society for Environmental Economics and Policy Studies 2021

\section{Correction to: Environmental Economics and Policy Studies https://doi.org/10.1007/s10018-021-00302-0}

In the original publication of the article, first and second author's affiliations were published incorrectly. The correct affiliations are provided below,

First author Sung Hyun Jun's affiliation should read as "Department of Economics, Seoul National University, Republic of Korea".

Further, second author Jee Young Kim's affiliation should read as "Department of International Economics and Trade, Sun Moon University, Republic of Korea".

The original article was updated.

Publisher's Note Springer Nature remains neutral with regard to jurisdictional claims in published maps and institutional affiliations.

The original article can be found online at https://doi.org/10.1007/s10018-021-00302-0.

Hyungna Oh

h.oh@khu.ac.kr

1 Department of Economics, Seoul National University, Seoul, Republic of Korea

2 Department of International Economics and Trade, Sun Moon University, Asan, Republic of Korea

3 Kyung Hee University, Yongin, Gyeonggi, Republic of Korea 